\title{
Perencanaan Perawatan Mesin Kompresor Pada PT. Es Muda Perkasa Dengan Metode Reliability Centered Maintenance (RCM)
}

\author{
Ikramullah Zein $^{1 *}$, Dewi Mulyati², Ilham Saputra ${ }^{3}$ \\ 1,2,3Program studi Teknik Industri, Fakultas Teknik, Universitas Serambi Mekkah \\ *Koresponden email: ikramullah.zein@serambimekkah.ac.id
}

Diterima: 26 Desember 2018

Disetujui : 26 Januari 2019

\begin{abstract}
Compressor at PT. Es Muda Perkasa that commonly failure is at unit D. So that need to optimize the compressor at unit $\mathrm{D}$ with finding the failure of the parts of the compressor and making the schedule of maintenance program to minimize the failure of the ice machine. This study using Reliability Centered Maintenance (RCM) method, which applicate Grey FMEA to determine the priority of the machine maintenance. After conducting and implementing the RCM method, it was found that the failure occurs at Low-Pressure and High-Pressure Pump at compressor unit D, and sub-part failure happen on bearing, due to small coefficient, which is 0.566 where it become primarily failure component. For the next maintenance, using schedule on condition task on bearing parts of the machine could minimize the failure of the parts on the machine.
\end{abstract}

Keywords: Grey FMEA, maintenance, Reliability Centered Maintenance (RCM)

\begin{abstract}
Abstrak
Mesin kompresor yang sering mengalami kerusakan pada PT. Es Muda Perkasa adalahkompresor pada unit D. Sehingga perlu mengoptimalkan kinerja kompresor unit D dengan mencari penyebab terjadinya kegagalan fungsi yang diakibatkan oleh komponen kritis dan sub komponennya, serta perbaikan program perawatan untuk meminimalisir kegagalan pada mesin pembuatan es tersebut. Penelitian ini menggunakan Metode Reliability Centered Maintenance (RCM) yang mengaplikasikan Grey FMEA untuk menentukan prioritas perbaikan pada mesin tersebut. Setelah dilakukannya penerapan metode RCM tersebut,ditemukannya kegagalan fungsi yang terjadi pada mesin kompresor unit D yaitu pada komponen Pompa Low Pressure (LP) \& Hight Pressure (HP) dan sub komponennya yaitu bearing karena memiliki koefisien terkecil sebesar 0,566 dimana yang menjadi komponen utama kegagalan. Untuk melakukan program perawatan selanjutnya, untuk meminimalisir kegagalan pada komponen bearing pada mesin digunakan Schedule on Condition Task.
\end{abstract}

Kata Kunci: Grey FMEA, Perawatan, Reliability Centered Maintenance (RCM)

\section{Pendahuluan}

Suatu mesin terdiri dari berbagai komponen vital yang mendukung kelancaran operasi, sehingga apabila komponen tersebut mengalami kerusakan maka akan mendatangkan kerugian yang sangat besar bagi perusahaan. Oleh sebab itu, Kegiatan perawatan mempunyai peranan yang sangat penting dalam mendukung beroperasinya suatu sistem secara lancar sesuai yang dikehendaki. Kegiatan perawatan juga dapat meminimalkan biaya atau kerugian-kerugian yang ditimbulkan akibat adanya kerusakan mesin. Oleh karena itu, tidak bisa dipungkiri perlunya suatu perencanaan kegiatan perawatan bagi masing-masing mesin produksi untuk memaksimalkan sumberdaya yang ada. Pada dasarnya terdapat dua kegiatan pokok dalam perawatan yaitu perawatan preventif dan perawatan korektif.

Reliability Centered Maintenance (RCM) adalah dasar dari perawatan fisik dan suatu teknik yang digunakan untuk mengembangkan proses perawatan pencegahan (preventive maintenance) yang terjadwal. (Ben-Daya, 2000) Hal ini didasarkan pada prinsip bahwa keandalan dari peralatan dan struktur dari kinerja yang akan dicapai adalah fungsi dari perancangan dan kualitas pembentukan perawatan pencegahan yang efektif akan menjamin terlaksananya desain keandalan dari peralatan (Moubray, 1997)

PT. Es Muda Perkasa adalah sebuah perusahaan yang bergerak dalam bidang pembuatan es balok, yang mana mengubah cairan (air) menjadi air yang padat yang biasanya disebut dengan es. Mesin pembuatan es balok pada perusahaan ini sering mengalami kerusakan dan 
Tabel 1. Data waktu kerusakan (breakdown) mesin kompresor PT. Es Muda Perkasa

\begin{tabular}{ccccc}
\hline \multirow{2}{*}{ Bulan } & \multicolumn{3}{c}{ Total Waktu Frekuensi Kerusakan (Jam) } \\
\cline { 2 - 5 } & Unit A & Unit B & Unit C & Unit D \\
\hline Januari & 3 & 2 & 2 & 8 \\
Februari & 4 & 1 & 3 & 2 \\
Maret & 7 & 5 & 3 & 4 \\
April & 2 & 4 & 1 & 5 \\
Mei & 2 & 2 & 1 & 6 \\
Juni & 4 & 2 & 1 & 7 \\
Juli & 3 & 1 & 4 & 4 \\
Agustus & 2 & 2 & 1 & 7 \\
September & 3 & 6 & 2 & 9 \\
Oktober & 4 & 3 & 3 & 5 \\
November & 2 & 1 & 2 & 3 \\
Desember & 3 & 1 & 3 & 11 \\
\hline Total & 39 & 30 & 26 & 71 \\
\hline
\end{tabular}

Sumber: PT. Es Muda Perkasa 2017

harus dilakukan breakdown. Hal ini menjadi penghambat jalannya proses produksi, sehingga berdampak pada penurunan kapasitas produksi. Pada saat dilakukan penelitian, PT. Es Muda Perkasa menerapkan sistem pemeliharaan corrective maintenance, yaitu melakukan perbaikan ketika terdapat kerusakan.

Penelitian ini bertujuan untuk mengoptimalkan kinerja komponen mesin kompresor pembuat es balok, sehingga waktu breakdown saat melakukan perbaikan pada salah satu komponen mesin tersebut tidak membutuhkan waktu yang lama dan dapat meningkatkan kapasitas produksi dengan cara melakukan preventive maintenance dengan menggunakan metode Reliability Centered Maintenance. Dengan metode ini diharapkan dapat mendeteksi lebih awal komponen-komponen kritis pada mesin pembuat es balok pada PT. Es Muda Perkasa.

\section{Tinjauan Pustaka}

Maintenance atau dalam Bahasa Indonesia disebut dengan perawatan adalah suatu kegiatan untuk memelihara atau menjaga fasilitas maupun mengadakan perbaikan, penyesuaian atau penggantian, agar terdapat suatu keadaan operasi produksi yang memuaskan sesuai dengan apa yang diharapkan (Kurniawan \& Fajar, 2013) (Manzini, 2010) (Fitri, 2010) Perawatan ini bertujuan untuk mencegah dan mengurangi ataupun menghindari kerusakan dari peralatan dengan memastikan tingkat keandalan dan kesiapan serta meminimalkan biaya perawatan (Ansori, et al., 2013) perawatan ini juga bertujuan untuk menjamin ketersediaan, keandalan faasilitas secara ekonomis maupun teknis, sehingga dalam penggunaannya dapat dilaksanakan seoptimal mungkin. Perawatan juga memperpanjang usia fasilitas, menjamin kesiapan operasional fasilitas dan yang peling penting adalah menjamin keselamatan kerja, keamanan dalam penggunaannya (Sudrajat, 2011)

Berdasarkan kebijakan dalam melakukannya, maintenance dapat dibagi dalam beberapa cara, yaitu:
Preventive maintenance, breakdown maintenance, schedule maintenance, predictive maintenance, dan yang terakhir adalah corrective maintenance.

\subsection{Preventive Maintenance}

Preventive maintenance merupakan perawatan yang direncanakan dan dilakukan sebelum terjadinya kerusakan pada suatu bagian mesin atau peralatan. Kegiatan ini dapat menjamin keandalan dari suatu bagian maupun keseluruhan bagian mesin dan juga dapat menjamin keselamatan bagi pemakai mesin atau peralatan tersebut.

Tingkat reliability dari kompressor sutau mesin dapat ditingkatkan hingga $90 \%$, tingkat keandalan drain valve dan oil filter naik sebesar $21,77 \%$ dan $33,34 \%$, secara berurutan, dengan melakukan preventive maintenance yang rutin. Biaya perawatan untuk 2 jenis komponen pada kompresor tersebut juga dapat diturunkan hingga mencapai $40,13 \%$ untuk drain valve dan $24,45 \%$ untuk komponen oil filter (Fitri, 2010)

\subsection{Breakdown Maintenance}

Breakdown maintenance dapat diartikan sebagai suatu kegiatan perawatan yang dilakukan ketika mesin atau peralatan yang digunakan telah rusak, perawatan ini bisa melakukan perbaikan pada mesin tersebut, bisa juga dengan menggantikan mesin atau bagian mesin yang perlu dilakukan perawatan. Kegiatan perawatan ini sangat merugikan karena dapat menimbulkan biaya yang tinggi dan waktu down time yang lama.

\subsection{Schedule Maintenance}

Perawatan ini dilakukan dalam rentang waktu tertentu sesuai dengan jadwal yang telah ditetapkan. Perawatan ini terjadi dikarenakan berdasarkan

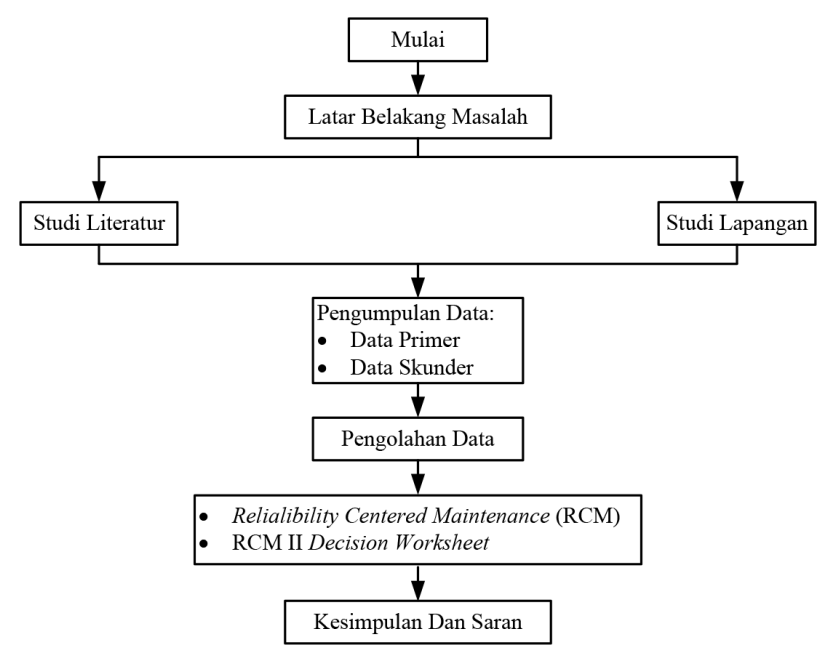

Gambar 1. Tahapan penelitian pada PT. Es Muda Perkasa 
Tabel 2. Batasan sistem komponen mesin PT. Es Muda Perkasa

\begin{tabular}{|c|c|c|}
\hline \multirow{2}{*}{ Komponen } & \multicolumn{2}{|c|}{ Batasan Fisik Primer } \\
\hline & Start With & Terminate With \\
\hline Control Panel & $\begin{array}{c}\text { Switch on dinyalakan dan arus litrik } \\
\text { mengair ke contactor dan solenoid } \\
\text { valve }\end{array}$ & Contactor penghubung koneksi kabel \\
\hline $\begin{array}{c}\text { Pompa Low } \\
\text { Pressure (LP) \& } \\
\text { Hight Pressure } \\
\text { (HP) }\end{array}$ & Coupling shaft bergerak & $\begin{array}{l}\text { Hasil putaran shaft membuat gear } \\
\text { bergerak dan blade pompa berputar } \\
\text { oleh kerja piston yang ada dalam } \\
\text { kompresor sehingga terjadi } \\
\text { perbedaan tekanan tinggi kondensor } \\
\text { (HP) dan tekanan rendah di } \\
\text { evaporator (LP) }\end{array}$ \\
\hline Oil Box & Pompa oli beroperasi & Oli mendinginkan mesin \\
\hline Motor & $\begin{array}{c}\text { Transmisi daya motor di } \\
\text { transmisikan menggunakan karet } \\
\text { coupling }\end{array}$ & $\begin{array}{l}\text { Hasil trasmisi motor menggerakan } \\
\text { pompa LP \& HP }\end{array}$ \\
\hline
\end{tabular}

pengalaman atau rekomendasi dari pabrik pembuat mesin atau peralatan yang bersangkutan.

\subsection{Predictive Maintenance}

Predictive maintenance melakukan kegiatan perawatannya berdasarkan hasil dari monitoring berkala mesin atau komponen mesin. Sehingga, keandalan mesin ataupun komponen mesin dapat terus dijaga.

\subsection{Corrective Maintenance}

Corrective maintenance adalah kegiatan pemeliharaan dan perawatan yang dilakukan setelah terjadinya kerusakan pada mesin atau peralatan, sehingga peralatan dan mesin dapat berfungsi dengan baik (Ansori, et al., 2013)

\subsection{Reliability Centered Maintenance}

Reabililty centered maintenance adalah suatu proses yang dilakukan untuk menentukan apa saja

Tabel 3. System Work Breakdown Structure

\begin{tabular}{|c|c|c|c|}
\hline Kode & Komponen & Kode & Sub Komponen \\
\hline \multirow{2}{*}{ A } & \multirow{2}{*}{ Control Panel } & A.1 & Kontaktor \\
\hline & & A. 2 & Katup Solenoid \\
\hline \multirow{2}{*}{$\mathrm{B}$} & $\begin{array}{c}\text { Pompa Low } \\
\text { Pressure (LP) \& }\end{array}$ & B.1 & Bantalan (Bearing) \\
\hline & $\begin{array}{c}\text { Hight Pressure } \\
\text { (HP) }\end{array}$ & B. 2 & Paking Pompa \\
\hline \multirow{2}{*}{$\mathrm{C}$} & \multirow{2}{*}{ Oil Box } & C. 1 & Paking Oil Box \\
\hline & & C. 2 & Pipa \\
\hline \multirow{3}{*}{$\mathrm{D}$} & \multirow{3}{*}{ Motor } & D.1 & Bantalan (Bearing) \\
\hline & & D. 2 & Lilitan Tembaga \\
\hline & & D.3 & Coupling \\
\hline
\end{tabular}

yang harus dilakukan agar dapat mencegah terjadinya kegagalan untuk memastikan bahwa alat atau mesin dapat bekerja optimal saat di butuhkan (N.S., et al., 2014) yang mana tujuan utama dari RCM adalah untuk mempertahankan fungsi mengidentifikasi mode kegagalan (failure mode) dan memprioritaskan tingkat kepentingan dari mode kegagalan. Lalu selanjutnya dilakukan pemilihan tindakan perawatan pencegahan yang efektif dan dapat diterapkan.

\section{Metode Penelitian}

Penelitian ini dilakukan pada PT. Es Muda Perkasa yang berlokasi di Jl. Cut Nyak Dhien, Desa Ajun, Kec. Peukan Bada Aceh Besar. Data yang diambil untuk penelitian ini adalah data waktu downtime kerusakan komponen mesin yang terjadi pada tahun 2017 yang dimulai dari bulan Jauuari sampai dengan Desember

Tabel 4. Nilai perhitungan seri perbandingan

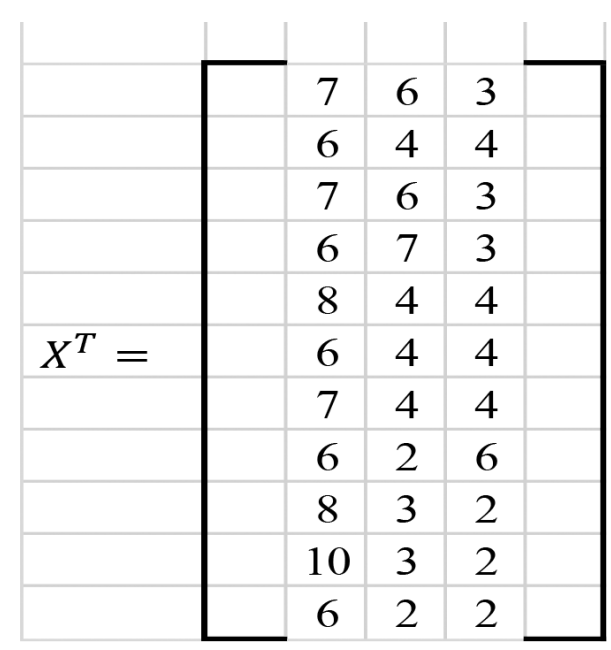


Tabel 5. Nilai perhitungan perbendaan antara seri standar dan seri perbandingan

\begin{tabular}{lll}
\hline$\Delta_{01}(1)=5$ & $\Delta_{01}(2)=4$ & $\Delta_{01}(3)=1$ \\
$\Delta_{02}(1)=4$ & $\Delta_{02}(2)=2$ & $\Delta_{02}(3)=2$ \\
$\Delta_{03}(1)=5$ & $\Delta_{02}(2)=4$ & $\Delta_{03}(3)=1$ \\
$\Delta_{04}(1)=4$ & $\Delta_{04}(2)=5$ & $\Delta_{04}(3)=1$ \\
$\Delta_{05}(1)=6$ & $\Delta_{05}(2)=2$ & $\Delta_{05}(3)=2$ \\
$\Delta_{06}(1)=4$ & $\Delta_{06}(2)=2$ & $\Delta_{06}(3)=2$ \\
$\Delta_{07}(1)=5$ & $\Delta_{07}(2)=2$ & $\Delta_{07}(3)=2$ \\
$\Delta_{08}(1)=4$ & $\Delta_{08}(2)=0$ & $\Delta_{08}(3)=4$ \\
$\Delta_{09}(1)=6$ & $\Delta_{09}(2)=1$ & $\Delta_{09}(3)=0$ \\
$\Delta_{10}(1)=8$ & $\Delta_{10}(2)=1$ & $\Delta_{10}(3)=0$ \\
$\Delta_{11}(1)=4$ & $\Delta_{11}(2)=0$ & $\Delta_{11}(3)=0$ \\
\hline
\end{tabular}

2018. Data total waktu kerusakan dapat dilihat pada tabel 1. berikut:

Dari data Tabel 1. Menunjukkan bahwa mesin yang berada pada unit D paling sering mengalami kerusakan dan waktu frekuensi kerusakannya juga lebih lama dibandingkan dengan Unit A, B dan C. Maka penelitian ini hanya mengkhususkan penyelidikannya pada Unit D saja.

\subsection{Tahapan Penelitian}

Adapun tahapan-tahapan penelitian yang dilakukan dapat dilihat pada gambar bagan alir dibawah ini.

\subsection{Penentuan Sistem}

Pada penelitian ini ditentukan bahwa batasan sistem penelitian ini adalah pada komponen mesin kompresor unit D. Batasan system komponen terdiri dari start with dan terminate with Pada Tabel 2. menunjukkan batasan sistem komponen mesin pada PT. Es Muda Perkasa.

\begin{tabular}{ccc}
$\begin{array}{c}\text { Tabel 6. Nilai perhitungan koefisien relasional grey dan derajat } \\
\text { hubungan grey }\end{array}$ & \\
\hline$\gamma_{01}(1)=0,444$ & $\gamma_{01}(2)=0,500$ & $\gamma_{01}(3)=0,800$ \\
$\gamma_{02}(1)=0,500$ & $\gamma_{02}(2)=0,800$ & $\gamma_{02}(3)=0,714$ \\
$\gamma_{03}(1)=0,444$ & $\gamma_{02}(2)=0,500$ & $\gamma_{03}(3)=0,800$ \\
$\gamma_{04}(1)=0,500$ & $\gamma_{04}(2)=0,444$ & $\gamma_{04}(3)=0,714$ \\
$\gamma_{05}(1)=0,364$ & $\gamma_{05}(2)=0,667$ & $\gamma_{05}(3)=0,667$ \\
$\gamma_{06}(1)=0,500$ & $\gamma_{06}(2)=0,800$ & $\gamma_{06}(3)=0,714$ \\
$\gamma_{07}(1)=0,444$ & $\gamma_{07}(2)=0,667$ & $\gamma_{07}(3)=0,667$ \\
$\gamma_{08}(1)=0,500$ & $\gamma_{08}(2)=1,000$ & $\gamma_{08}(3)=0,385$ \\
$\gamma_{09}(1)=0,364$ & $\gamma_{09}(2)=0,800$ & $\gamma_{09}(3)=0,556$ \\
$\gamma_{10}(1)=0,333$ & $\gamma_{10}(2)=0,800$ & $\gamma_{10}(3)=1,000$ \\
$\gamma_{11}(1)=0,500$ & $\gamma_{11}(2)=1,000$ & $\gamma_{11}(3)=1,000$
\end{tabular}

Tabel 7. Nilai perhitungan derajat hubungan grey

$$
\begin{array}{ll}
\Gamma_{01}=0,581 & \Gamma_{07}=0,592 \\
\Gamma_{02}=0,671 & \Gamma_{08}=0,628 \\
\Gamma_{03}=0,581 & \Gamma_{09}=0,573 \\
\Gamma_{04}=0,581 & \Gamma_{10}=0,711 \\
\Gamma_{05}=0,566 & \Gamma_{11}=0,833 \\
\Gamma_{06}=0,671 &
\end{array}
$$

\subsection{Penentuan Batasan Sistem}

Berdasarkan penjabaran sistem ke dalam sub sistem maka dapat dibentuk suatu System Work Breakdown Structure (SWBS) atau yang disebut dengan struktur kerusakan sistem kerja. Dalam SWBS, kita menjabarkan komponen-komponen utama yang berhubungan dengan fungsi sistem. System Work Breakdown Structure untuk komponen mesin unit D ini ditunjukkan pada Tabel 3.

Perhitungan Grey FMEA dapat dilakukan untuk menentukan prioritas perbaikan mesin. Perhitungan grey FMEA ini dilakukan dengan beberapa langkah.

\subsection{Langkah Perhitungan Grey FMEA 3.4.1 Membangun Seri Perbandingan}

Pada tahap ini adalah memasukkan nilai Severity, Occurrence, dan Detection pada masing-masing tipe kecacatan.

\subsubsection{Menetapkan Seri Standar $\left(\mathrm{X}_{0}\right)$}

Standar yang ditetapkan adalah nilai terkecil yang terdapat pada Severity, Occurance, dan Detection (Eddy, 2015) Maka nilai seri standar pada penelitian ini yang diambil adalah 2 .

$$
\mathrm{X}_{0}=\left(\begin{array}{lll}
2 & 2 & 2
\end{array}\right)
$$

\subsubsection{Mencari Perbedaan Antara Seri Standar Dan Seri Perbandingan}

Pada tahap ini dilakukan dengan mengurangi nilai dari seri perbandingan $\left(\mathrm{X}_{\mathrm{T}}\right)$ dengan seri standar $\left(\mathrm{X}_{0}\right)$. Maka hasilnya adalah:

\subsubsection{Menghitung Koefisien Relasional Grey dan Derajat Hubungan Grey}

Pada langkah keempat ini yang dilakukan adalah mencari koefisien grey $\left(\gamma_{0 i}\right)$, Nilai pada $\Delta_{\max }$ diperoleh dari bobot terbesar yaitu 8 dan nilai pada $\Delta_{\min }$ diperoleh dari bobot terkecil yaitu $0, \varsigma$ adalah berupa identifikasi, hanya mempengaruhi nilai relatif dari resiko tanpa mengubah prioritas. Nilai yang digunakan adalah 0,5 . Maka diperoleh hasil sebagai berikut: 


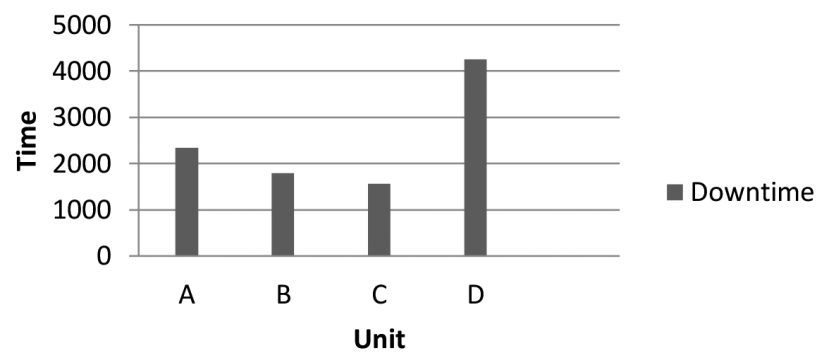

Gambar 2. Diagram kerusakan mesin PT. Es Muda Perkasa

$\gamma_{0 i}=\frac{\Delta_{0 i} \min +\zeta \Delta_{0 i} \max }{\Delta_{0 i} j+\zeta \Delta_{0 i} \max }$

\subsubsection{Menghitung Derajat Hubungan Grey $\left(\Gamma_{01}\right)$}

Langkah kelima dilakukan untuk mengetahui nilai prioritas untuk masing-masing komponen:

$$
\Gamma_{0 \mathrm{i}}(\mathrm{j})=\frac{1}{3} \underset{j=1}{\stackrel{3}{3} \gamma_{0 \mathrm{i}} j}
$$

\subsubsection{Pemilihan Tindakan}

Pemilihan tindakan merupakan tahap terakhir dari proses RCM. Dari tiap mode kerusakan dibuat daftar tindakan menggunakan RCM II Decision Worksheet yang mungkin untuk dilakukan dan selanjutnya memilih tindakan yang paling efektif. Berdasarkan langkah-langkah sebelumnya yang telah dilakukan, maka diperoleh komponen yang paling kritis yang tergolong time directed maintenance atau kegiatan perawatan yang dilakukan berdasarkan variabel waktu. Komponen yang tergolong time directed adalah Pompa Low Pressure (LP) \& Hight Pressure (HP) serta sub komponennya yaitu bantalan (bearing).

\section{Hasil dan Pembahasan}

Berdasarkan hasil pengumpulan data, data yang digunakan yaitu data pada periode Januari 2016 sampai Desember 2017, yaitu data waktu downtime, yang mendukung dalam pemecahan masalah maka sistem yang dipilih adalah sistem yang memiliki kriteria total frekuensi kerusakan dan downtime terbesar yang ditunjukkan pada Gambar 2.

\subsection{Grey Failure Mode dan Effect Analysis}

Setelah mendapatkan sub komponen kritis dengan diagram pareto, maka langkah selanjutnya adalah membuat Failure Mode Effects And Analysis (FMEA) yaitu membuat pembobotan pada Severity (tingkat bahaya), Occurrence (tingkat kejadian) dan Detectability (tingkat deteksi) untuk mendapatkan besarnya nilai Risk Priority Number (RPN). RPN merupakan produk matematis dari keseriusan effect (severity), kemungkinan terjadinya cause akan menimbulkan kegagalan yang berhubungan dengan effect (occurrence), dan kemampuan untuk mendeteksi kegagalan sebelum terjadi (detection) yang digunakan sebagai input perhitungan grey FMEA.

Mengurutkan tingkat resiko berdasarkan prioritas

Tabel 8. Diagram FMEA sub komponen kompresor unit D

\begin{tabular}{|c|c|c|c|c|c|c|}
\hline \multirow{2}{*}{$\begin{array}{c}\text { Komponen } \\
\text { Utama }\end{array}$} & \multirow{2}{*}{ Sub Komponen } & \multirow{2}{*}{ Jenis Kegagalan } & \multicolumn{3}{|c|}{ Bobot } & \multirow{2}{*}{ RPN } \\
\hline & & & Sev & Occ & Det & \\
\hline \multirow{4}{*}{ Control Panel } & \multirow[b]{2}{*}{ Kontaktor } & Kontaktor Terbakar & 7 & 6 & 3 & 126 \\
\hline & & Kontaktor LP Stage Trip & 6 & 4 & 4 & 36 \\
\hline & & Katup Solenoid Bocor & 7 & .6 & 3 & 126 \\
\hline & Katup Solenoid & Katup Solenoid Terbakar & 6 & .7 & 3 & 126 \\
\hline \multirow[t]{2}{*}{ Pompa LP \&HP } & Bantalan (bearing) & $\begin{array}{c}\text { Bearing pompa } \\
\text { Kehilangan Penjajaran } \\
\text { (miss aligment) dan Susut } \\
\text { karna Tergosok }\end{array}$ & 8 & 4 & 4 & 128 \\
\hline & Paking & $\begin{array}{c}\text { Paking Air Condensat } \\
\text { Sobek }\end{array}$ & 6 & 4 & 4 & 96 \\
\hline \multirow{2}{*}{ Oil Box } & Paking & Paking Oil Box Sobek & 7 & 4 & 4 & 112 \\
\hline & Bearing & Paking Oil Box Bocor & 6 & 2 & 6 & 72 \\
\hline \multirow{3}{*}{ Motor } & Bearing & $\begin{array}{l}\text { Bearing Motor Susut } \\
\text { karna Tergosok dan } \\
\text { Kehilangan Penjajaran }\end{array}$ & 8 & 3 & 2 & 48 \\
\hline & Lilitan Tembaga & $\begin{array}{c}\text { Lilitan Tembaga Motor } \\
\text { Terbakar }\end{array}$ & 10 & 3 & 2 & 60 \\
\hline & Coupling & Karet Kopling Sobek & 6 & 2 & 2 & 24 \\
\hline
\end{tabular}


Tabel 9. Rangking prioritas kerusakan mesin berdasarkan hubungan antara nilai derajat hubungan dan derajat hubungan

\begin{tabular}{ccc}
\hline $\begin{array}{c}\text { Nilai Derajat } \\
\text { Hubungan }\end{array}$ & Derajat Hubungan & Rangking \\
\hline 0,566 & $\Gamma_{05}$ & 1 \\
0,573 & $\Gamma_{09}$ & 2 \\
0,581 & $\Gamma_{01}$ & 3 \\
0,581 & $\Gamma_{03}$ & 4 \\
0,581 & $\Gamma_{04}$ & 5 \\
0,592 & $\Gamma_{07}$ & 6 \\
0,628 & $\Gamma_{08}$ & 7 \\
0,671 & $\Gamma_{02}$ & 8 \\
0,671 & $\Gamma_{06}$ & 9 \\
0,711 & $\Gamma_{10}$ & 10 \\
0,833 & $\Gamma_{11}$ & 11 \\
\hline
\end{tabular}

pengolahan data yang dilakukan maka didapat perbandingan mulai dari hasil terkecil dari ke-11 faktor penyebab tersebut dapat dilihat pada Tabel 9. Maka didapat prioritas pertama merupakan prioritas dengan derajat hubungan terkecil yaitu $\Gamma 05$ karena memiliki koefisien terkecil sebesar 0,566 dimana yang menjadi prioritas resiko utama adalah gangguan pada bantalan (bearing) pompa yang mengalami kerusakan karena bantalan kehilangan penjajaran (miss aligment) atau kurangnya pelumasan, dan susut karena aus. karena adanya vibrasi tinggi atau faktor usia komponen bantalan (bearing).

\subsection{RCM II Decision Worksheet}

Setelah diketahui kegagalan pada mesin dapat dilihat di Tabel 10. maka selanjutnya akan direncanakan perawatan menggunakan RCM II Decision Worksheet, yaitu merupakan dokumen lembar kerja kedua dalam pengerjaan RCM. Dalam membantu proses pengambilan keputusan, RCM menggunakan dua dokumen utama, yakni lembar informasi RCM dan lembar keputusan RCM.

\subsubsection{Information Worksheet}

Information Worksheet atau lembar informasi RCM merupakan dokumen yang berisi informasi rinci tentang fungsi dan kinerja standar, kegagalan fungsional, model kegagalan, dan dampak kegagalan sebagaimana Tabel 11.

\subsubsection{Decision Worksheet}

Keputusan akhir dari kegiatan maintenance pada Kompresor Unit D di PT. Es Muda Perkasa dapat dilihat pada decision worksheet pada Tabel 12. Tabel ini menunjukkan kolom Information Reference mengacu pada informasi yang diperoleh dari FMEA atau RCM II Information Worksheet, kolom Consequences Evaluation yang menunjukkan konsekuensi yang ditimbulkan karena terjadinya kegagalan fungsi. Kolom Proactive task \& Default Action menunjukkan tindakan atau kondisi yang diambil dalam mencegah terjadinya failure mode. Kolom Proposed Task yaitu kolom yang menunjukkan catatan tindakan yang dilakukan sebelum terjadinya kegagalan. Kolom Initial Interval menunjukkan catatan interval perawatan

Tabel 10. Fungsi Sistem dan Kegagalan Fungsi

\begin{tabular}{lll}
\hline No. Fungsi & $\begin{array}{l}\text { No. Kegagalan } \\
\text { Fungsi }\end{array}$ & Uraian Fungsi atau Kegagalan Fungsi \\
\hline A.1 & A.1.1 1.2 & $\begin{array}{l}\text { Contactor terbakar dan trip mengakibatkan tidak } \\
\text { berfungsinya pemindahan mesin } \\
\text { Contactor trip mengakibatkan tidak berfungsinya } \\
\text { pemindahan daya dan pompa }\end{array}$ \\
\hline A.2 & A.2.1 & $\begin{array}{l}\text { Katup Solenoid terbakar mengakibatkan pompa } \\
\text { tidak bisa menambah kecepatan putaran }\end{array}$ \\
\hline B.1 & A.2.1 & $\begin{array}{l}\text { Katup Solenoid terbakar mengakibatkan pompa tidak } \\
\text { bisa menambah kecepatan putaran }\end{array}$ \\
\hline B.2 & B.1.1 1.2 & $\begin{array}{l}\text { Bantalan (Bearing) pompa miss aligment atau aus } \\
\text { menyebabkan tidak berfungsinya putaran pompa } \\
\text { dengan baik }\end{array}$ \\
\hline C.1 & C.1.1 & Terjadinya kebocoran pada pompa \\
\hline C.2 & C.1.2 & $\begin{array}{l}\text { Paking oil box sobek mengakibatkan kebocoran dan } \\
\text { mengurangi pendingan pada mesin }\end{array}$ \\
\hline D.1 & D.1.2 & Tidak terkirimnya oli untuk pendinginan \\
\hline D.2 & D.2.1 & Tidak berputarnya poros shaft \\
\hline D.3 & D.3.1 & $\begin{array}{l}\text { Tidak berputarnya berfungsinya motor } \\
\text { motor bisa mentransmisikan daya yang diberikan }\end{array}$ \\
\hline
\end{tabular}


Tabel 11. Information worksheet kompresor unit D

\begin{tabular}{|c|c|c|c|c|c|c|c|c|c|}
\hline \multirow{2}{*}{\multicolumn{2}{|c|}{$\begin{array}{c}\text { RCM II INFORMATIONA } \\
\text { WORKSHEET KOMPRESOR } \\
\text { PT. ES MUDA PERKASA }\end{array}$}} & \multicolumn{4}{|c|}{ KOMPRESOR UNIT D } & \multirow{3}{*}{ 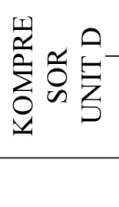 } & \multirow{2}{*}{\multicolumn{2}{|c|}{$\begin{array}{c}\text { FACILITATOR } \\
\text { AUDITOR: } \\
\text { MEKANIK DAN } \\
\text { ELEKTRIK }\end{array}$}} & \multirow{2}{*}{$\begin{array}{l}\text { DATE: } \\
D A T E:\end{array}$} \\
\hline & & \multicolumn{4}{|c|}{ UNIT D } & & & & \\
\hline \multirow{2}{*}{\multicolumn{2}{|c|}{ FUNCTION }} & \multicolumn{2}{|c|}{ FUNCTIONAL FAILURE } & \multicolumn{2}{|r|}{ FAILURE MODE } & & \multicolumn{3}{|c|}{ FAILURE EFFECT } \\
\hline & & \multicolumn{2}{|r|}{ (Loss of Function) } & & (Cause of Failure) & \multicolumn{4}{|c|}{ Apa yang terjadi jika gagal } \\
\hline \multirow{2}{*}{1} & \multirow{2}{*}{$\begin{array}{l}\text { Untuk mentransfer aliran } \\
\text { listrik ke mesin dan } \\
\text { merubah kecepatan motor }\end{array}$} & A & Kontaktor terbakar & 1 & $\begin{array}{l}\text { Reaksi panas dan } \\
\text { adanya kotoran }\end{array}$ & Kompres & sor berhenti & & \\
\hline & & $\mathrm{B}$ & Kontaktor LP Stage Trip & 1 & $\begin{array}{l}\text { Reaksi panas dan } \\
\text { adanya kotoran }\end{array}$ & Kompres & sor berhenti & & \\
\hline \multirow{2}{*}{2} & \multirow{2}{*}{$\begin{array}{l}\text { Unutk membuka Tutup } \\
\text { Valve control hidrolik dan } \\
\text { pneumatic secara otomatis }\end{array}$} & A & Katup solenoid bocor & 1 & $\begin{array}{l}\text { Umur material dan } \\
\text { adanya reaksi panas }\end{array}$ & \multicolumn{4}{|c|}{ Tidak berfungsinya Valve Oli Otomatis } \\
\hline & & $\mathrm{B}$ & Katup solenoid terbakar & 1 & $\begin{array}{l}\text { Lilitan tembaga } \\
\text { terbakar }\end{array}$ & \multicolumn{4}{|c|}{ Tidak Berfungsinya Valve oli otomatis } \\
\hline 3 & $\begin{array}{l}\text { Sebagai bantalan poros } \\
\text { putar shaft pompa }\end{array}$ & A & $\begin{array}{l}\text { Bearing pompa } \\
\text { kehilangan penjajaran } \\
\text { dan susut lama tergosok }\end{array}$ & 1 & $\begin{array}{l}\text { Vibrasi tinggi dan } \\
\text { adanya reaksi panas }\end{array}$ & \multicolumn{4}{|c|}{ Kompresor berhenti } \\
\hline 4 & $\begin{array}{l}\text { Untuk mencegah terjadinya } \\
\text { kebocoran oli gear pompa }\end{array}$ & A & $\begin{array}{l}\text { Paking air condenser } \\
\text { sobek }\end{array}$ & 1 & Umur material & \multicolumn{4}{|c|}{ Kompresor berhenti } \\
\hline 5 & $\begin{array}{l}\text { Untuk memperapat } \\
\text { sambungan dan mencegah } \\
\text { terjadinya kebocoran oli } \\
\text { gear pompa }\end{array}$ & A & Paking oli box sobek & 1 & Umur material & \multicolumn{4}{|c|}{$\begin{array}{l}\text { Mesin kepanasan dan kompresor } \\
\text { berhenti }\end{array}$} \\
\hline 6 & $\begin{array}{l}\text { Untuk perapat sambungan } \\
\text { dari line sat uke line } \\
\text { lainnya }\end{array}$ & A & Pipa oli box bocor & 1 & $\begin{array}{l}\text { Minyak bertekanan } \\
\text { tinggi }\end{array}$ & $\begin{array}{l}\text { Mesin } \\
\text { berhenti }\end{array}$ & kepanasan & dan & kompresor \\
\hline 7 & $\begin{array}{l}\text { Untuk bantalan putar poros } \\
\text { shaft motor }\end{array}$ & A & $\begin{array}{l}\text { Bearing motor } \\
\text { kehilangan penjajaran } \\
\text { dan susut lama tergosok }\end{array}$ & 1 & $\begin{array}{l}\text { Kehilangan } \\
\text { penjajaran }\end{array}$ & \multicolumn{4}{|c|}{ Kompresor berhenti } \\
\hline 8 & $\begin{array}{l}\text { Untuk merubah naik dan } \\
\text { turnnya tegangan pada } \\
\text { motor }\end{array}$ & A & $\begin{array}{l}\text { Lilitan tembaga motor } \\
\text { terbakar }\end{array}$ & 1 & $\begin{array}{l}\text { Umur material dan } \\
\text { reaksi panas }\end{array}$ & \multicolumn{4}{|c|}{ Kompresor berhenti } \\
\hline 9 & $\begin{array}{l}\text { Untuk menghubungkan } 2 \\
\text { shaft guna menyalurkan } \\
\text { suatu gerak }\end{array}$ & A & Karet coupling sobek & 1 & $\begin{array}{l}\text { Umur material dan } \\
\text { vibrasi tinggi }\end{array}$ & \multicolumn{4}{|c|}{ Coupling putus } \\
\hline
\end{tabular}

yang optimal. Kolom Can be done by menunjukkan catatan data siapa yang diberikan wewenang dalam melaksanakan aktifitas perawatan tersebut.

Dimana:

$$
\begin{array}{ll}
\mathrm{F} & \begin{array}{l}
\text { : berfungsi (Functional) } \\
\text { FF }
\end{array} \\
& \begin{array}{l}
\text { Fegagaln berfungsi (Functional } \\
\text { Failure) }
\end{array} \\
\mathrm{FM} & \begin{array}{l}
\text { : Mode berfungsi (Functional Mode) } \\
\mathrm{H}
\end{array} \\
& \begin{array}{l}
\text { : Fungsi Tersembunyi (Hidden } \\
\text { Function) }
\end{array} \\
\mathrm{S} & \begin{array}{l}
\text { : Konsekuensi keselamatan (Safety } \\
\text { Consequences) }
\end{array} \\
\mathrm{E} & \text { : Bukti Fungsi (Evident Function) } \\
\mathrm{O} & \text { : Konsekuensi beroperasi } \\
& \text { (Operational Consequences) }
\end{array}
$$

\section{Kesimpulan}

Berdasarkan penelitian yang telah dilakukan di PT. Es Muda Perkasa Desa Ajun Kec. Pekan Bada, Aceh Besar, dan dianalisa menggunaka metode Reliability Centered Maintenance (RCM) maka didapatkan kesimpulan, yaitu:

1 Komponen kritis mesin kompresor unit D yaitu Pompa Low Pressure (LP) \& Hight Pressure (HP).

2 Sub komponen kritis kompresor unit D yaitu bantalan (bearing) pompa LP \& HP yang diakibatkan Kehilangan Penjajaran (miss aligment) dan Susut karena Tergosok.

3 Usulan perbaikan program perawatan untuk meminimasi kegagalan berdasarkan RCM II decision work sheet yang menyebabkan downtime mesin kompresor unit D pada komponen kritis pompa LP \& HP diperoleh Schedule On Condition Task sebagai tindakan perawatannya.

4 Komponen komponen yang tersebutkan diatas dapat diprediksi penggantiannya setiap

\section{Daftar Pustaka}

Albanna, M. H., 2016. http://mhasanalbana.blogspot.com. [Online] Available at: http://mhasanalbana.blogspot. com/2016/11/mengenal-proses-rapid-prototyping. 
Tabel 12. Decision Worksheet Kompresor Unit D

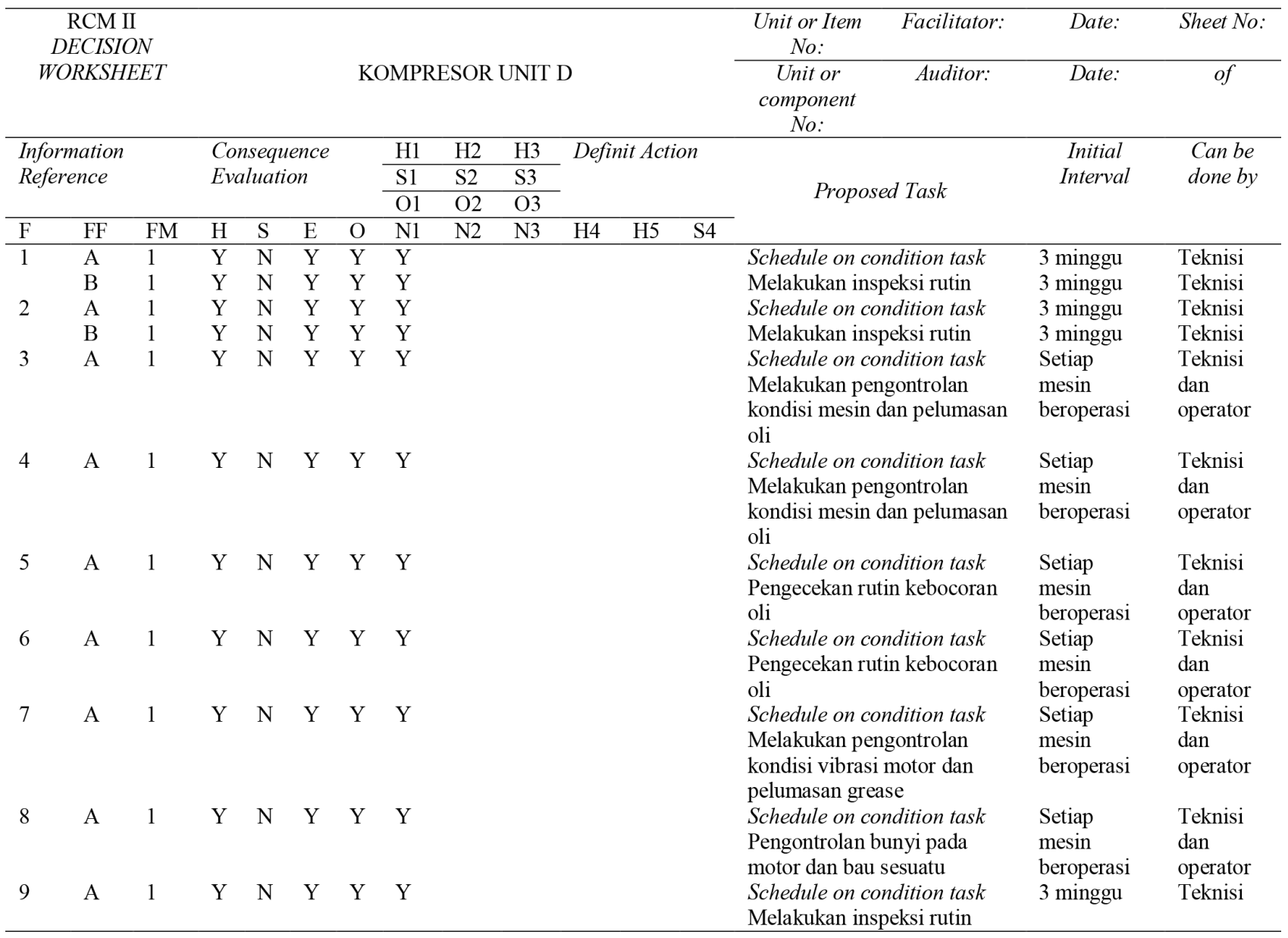

html [Accessed 26 November 2016].

Ansori, Nachnul, Mustajib \& Imron, M., 2013. Sisteem Perawatan Terpadu. Yogyakarta: Graha Ilmu.

Ben-Daya, M., 2000. You May Need RCM to Enhance TPM Implementation. Journal of Quality in Maintenance Engineering, pp. 82-85.

Daryus, A., 2007. Manajemen Pemeliharaan Mesin, Jakarta: Suryabrata.

Ebeling, C. E., 1997. An Introduction to Reliability and Maintainability Engineering. Singapore: The Mc. Graw Hills Company.

Eddy, W., 2015. Perancangan Preventive Maintenance pada Mesin Produksi di PT. Kharisma Abadi Sejati. Medan: Sekolah Tinggi Teknik Harapan.

Fitri, P., 2010. Optimasi Preventive Maintenance dan Penjadwalan Penggantian Komponen Mesin Kompressor dengan Menggunakan Mixed Integer Non Linier Programming dari Kamran. Jakarta: Universitas Indonesia.

Gaspersz, V., 2002. Pedoman Implementasi Program Six Sigma Terintegrasi dengn ISO 9001: 2000 $M B N Q A$ dan HCCP. Jakarta: PT. Gramedia Pustaka Utama.
Iriawan, N., 2006. Mengolah Data Statistik dengan Mudah Menggunakan Minitab 14. Yogyakarta: Andi.

Kurniawan \& Fajar, 2013. Manajemen Perawatan Industri; Teknik dan Aplikasi. Jakarta: Graha Ilmu.

Lange, K. A., Legget, S. C. \& Baker, B., 2001. Potential Failure and Effect Analysis. Michigan: AIAG Press.

Manzini, R., 2010. Maintenance for Industrial System. London : Springer.

Masruroh, N., 2008. Perencanaan Kegiatan Perawatan pada Unit Produksi Butiran (Padat) dengan Basic RCM (Reliabbility Center Maintenance) di PT. Petrokimia Gresik. Surabaya: Universitas Pembangunan Nasional.

Moubray, J., 1997. Reliability Center Maintenance. New York: Industrial Press.

N.S., A., Harsono, A. \& Mustofa, F. H., 2014. Usulan Kebijakan Perawatan Lokomotif Jenis CC201 dengan Menggunakan Metode Reliability Centerd Maintenance di PT. Kereta Ai Indonesia DIPO Bandung. Jurnal Teknik Industri Institute 
Teknologi Nasional, pp. 288-299.

Nasution, A. H., 2006. Manajemen Industri. Yogyakarta: Andi Offset.

Palit \& Cristian, H., 2012. Perancangan RCM untuk Mengurangi Downtime Mesin pada Perusahaan Manufaktur Aluminium. Surabaya, Petra Cristian University.

Pintelon, L., 1999. Case Study: RCM - Yes, No or Maybe?. Journal of Quality in Maintenance Engineering, 5(3), pp. 182-192.

Rosnani, G., 2007. Sistem Produksi. Yogyakarta: Graha Ilmu.

Smith, A. M. \& Hinchcliffe, G. R., 2004. RCM Gateway to world class Maintenance. London: Elsevier.

Soesetyo, I. \& Bendatu, L., 2014. Penjadwalan Predictive Maintenance dan Biaya Perawatan Mesin Pellet (Studi Kasus: PT. Charoen Pokphand Indonesia -Sepanjang). Jurnal Tirta, 2(2), pp. 147-154.

Sudrajat, A., 2011. Pedoman Praktis: Manajemen Perawatan Mesin Industri. Bandung: Refika Aditama.

Suryabrata, S., 2005. Metodologi Penelitian. Jakarta: PT. Raja Grafindo.

Walpole, R. E. \& Myers, R. H., 1995. Ilmu Peluang dan Statistika untuk Iinsinyur dan Ilmuan. Bandung: ITB. 